\title{
Preoperative transdural collateral vessels in moyamoya as radiographic biomarkers of disease
}

\author{
Armide Storey, BS, ${ }^{1}$ R. Michael Scott, MD, ${ }^{1}$ Richard Robertson, MD, ${ }^{2}$ and Edward Smith, MD ${ }^{1}$ \\ Departments of ${ }^{1}$ Neurosurgery and ${ }^{2}$ Radiology, Boston Children's Hospital and Harvard Medical School, Boston, Massachusetts
}

\begin{abstract}
OBJECTIVE The prevalence of angiographically evident preoperative transdural collateral vessels in moyamoya is not well documented. The authors hypothesized that transdural collaterals could be used as radiographic biomarkers of disease, and that their presence is associated with more advanced moyamoya arteriopathy at diagnosis, which is a harbinger of more frequent operative complications and a predictor of better long-term angiographic results following surgery.

METHODS The study consists of a single-institution case series of patients with moyamoya who underwent pial synangiosis between 2005 and 2013.

RESULTS Moyamoya was diagnosed in a total of 204 patients ( $n=121$ [59\%] female, 83 [41\%] male); the average age at surgery was 9.5 years (range $0.4-35$ years). Radiographically, $154(75 \%)$ had bilateral disease for a total of 308 affected hemispheres; 152 (75\%) had radiographic stroke; and 190 (93\%) had "ivy sign" on FLAIR MRI, indicating slow flow. Of the 358 hemispheres, 324 were treated operatively. On preoperative angiography, 107 patients (52\%) had transdural collaterals in 176 affected hemispheres (49\%). The Suzuki stage was higher in patients with collaterals $(3.4$ vs $3.0, p=$ 0.002). Of 324 treated hemispheres, $84(26 \%)$ had collaterals within the surgical field. Complications included 12 strokes (3.7\% stroke rate/hemisphere), with $5(42 \%)$ directly attributable to interruption of transdural collaterals. On 1-year postoperative arteriograms available in 222 hemispheres, Matsushima grades trended better in patients with preoperative collaterals (1.5 vs $1.8[A=1, B=2, C=3] ; p<0.003)$.

CONCLUSIONS Transdural collaterals are present in nearly half of all preoperative arteriograms in patients with moyamoya. These collaterals are more common in advanced disease, are associated with stroke as a perioperative complication, and may suggest increased capacity to produce surgical collaterals postoperatively. These data support the utility of preoperative arteriography.
\end{abstract}

https://thejns.org/doi/abs/10.3171/2016.9.PEDS16161

KEY WORDS moyamoya; transdural collaterals; angiogram; pediatric; cerebrovascular; revascularization; vascular disorders

I $\mathrm{N}$ patients with moyamoya the clinical significance of the presence of transdural collaterals, defined as blood supply to the cortex from branches of the external carotid artery (ECA), has not been widely investigated. Transdural collaterals are important to note preoperatively because their interruption during a revascularization procedure may result in stroke. Because the existence of spontaneous transdural collaterals appears to demonstrate the capacity of the brain to attract a new vascular supply, we hypothesized that evidence of this preoperative collateral could serve as a surrogate marker of moyamoya severity and might predict a robust response to revascularization.

This study was undertaken to determine the prevalence of transdural collaterals at diagnosis in a consecutive surgi- cal series, and their relationship to the outcome of surgical revascularization procedures. We anticipate that these new data will provide support for the continued use of catheter angiography in the evaluation of patients with moyamoya. Although angiography does not replace the use of other complementary imaging modalities (such as MRI or methods of quantitative cerebral perfusion analysis), our expectation is that this study will increase the diagnostic and prognostic capabilities of physicians treating patients with moyamoya.

\section{Methods}

A consecutive surgical series of patients with moya-

ABBREVIATIONS DSA = digital subtraction angiography; ECA = external carotid artery; ICA = internal carotid artery; MCA = middle cerebral artery; MMA = middle meningeal artery; STA = superficial temporal artery.

SUBMITTED March 13, 2016. ACCEPTED September 13, 2016

INCLUDE WHEN CITING Published online December 9, 2016; DOI: 10.3171/2016.9.PEDS16161. 
moya arteriopathy was reviewed to identify all patients with both moyamoya and preoperative catheter angiograms (including bilateral ECA and internal carotid artery [ICA] injections) who were treated with surgical revascularization between 2005 and 2013. Moyamoya was confirmed by the criteria outlined in the Japanese guidelines and recent pediatric evidence-based practice review. ${ }^{4,25} \mathrm{In}$ accordance with an IRB-approved protocol, medical records were retrospectively reviewed to determine patient demographic information, age at presentation and initial surgery, symptoms at presentation, comorbid conditions, results of radiographic studies, perioperative and late complications, and long-term outcomes.

The Suzuki staging system was used to stratify preoperative disease severity. ${ }^{4,27}$ Evidence of slow cortical flow was determined by the presence of sulcal hyperintensity on axial FLAIR images (ivy sign) on MRI., ${ }^{3,8,14}$ The Matsushima grade on postoperative digital subtraction angiography (DSA) and evidence of new postoperative infarct on MRI or CT (as compared with preoperative studies) were used to evaluate the outcome of this cohort. ${ }^{16}$

Transdural collaterals were defined as blood supply to the cortex from branches of the ECA, as determined by formal neuroradiology review. (Ophthalmic collateral vessels were excluded from this study because they originate from branches of the ICA and, from a practical standpoint, are not likely to ever be in a surgical revascularization operative field.) Transdural collaterals were characterized for each hemisphere by the primary parent artery (middle meningeal, superficial temporal, maxillary, or ethmoidal). The determination of collateralization was made as part of the routine radiology report, as dictated by the attending neuroradiologist at the time of the child's imaging, independent of the surgeon and included as part of the routine clinical interpretation of films. All cases had images available for review at the time of surgery and also for re-review during the preparation of this manuscript (all images are kept as part of the permanent medical record on our PACS system). All reports were confirmed by rereview at the time of manuscript preparation by the lead author (E.S.) and head of radiology (R.R.). If a patient had transdural collaterals from more than one source, then the vessel providing the largest supply was defined as the primary parent artery (Fig. 1). The systematic operative approach of pial synangiosis uses a reproducible surgical field under the parietal branch of the superficial temporal artery (STA), allowing the surgeon to reliably predict the presence of collateral branches in the field preoperatively. Transdural collaterals were considered to be within the surgical field if any part of the collateral supply could be physically disrupted within the area of the craniotomy (both cortical collaterals directly in view and also en passage vessels within the field that supply collaterals distally).

The operative approach in all patients was pial synangiosis, a modification of the encephaloduroarteriosynangiosis procedure developed by the senior author (R.M.S.). ${ }^{1}$ The approach uses the parietal branch of the STA for an indirect bypass and radiographic outcomes are standardized to the Matsushima grade (Fig. 2). ${ }^{17,18,22}$

Complications were defined specifically as periopera-

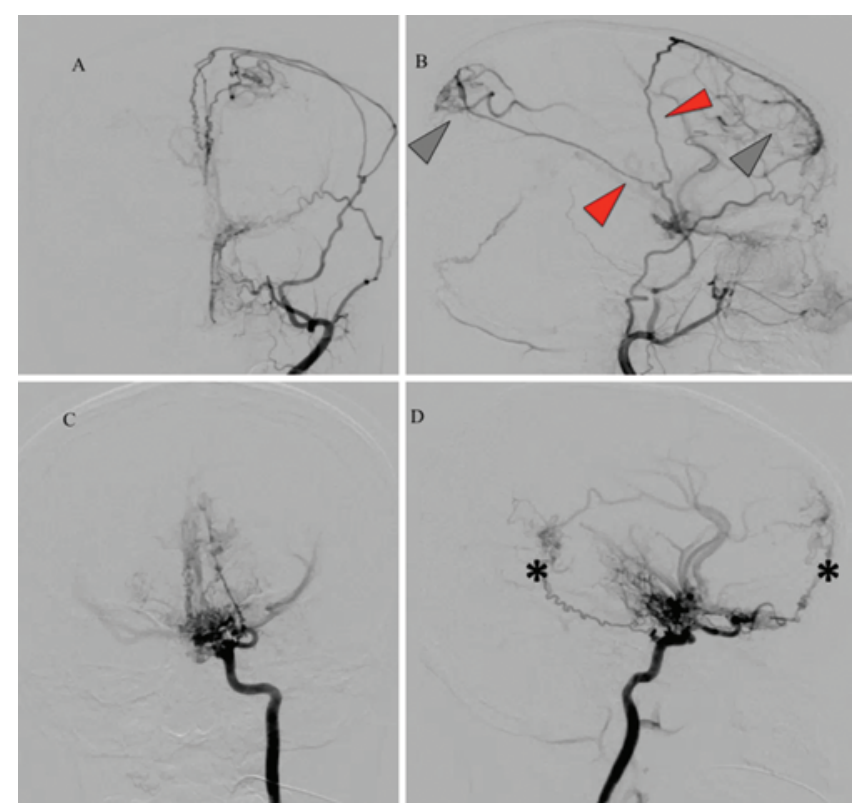

FIG. 1. Catheter angiograms demonstrating spontaneous transdural collaterals arising from the MMA. Anteroposterior $(\mathbf{A})$ and lateral $(B)$ views of left ECA injection. Note MMA (red arrowheads) providing spontaneous transdural collateral vessels to the parietal and frontal cortex (gray arrowheads). Anteroposterior (C) and lateral (D) views of left ICA injection from same patient demonstrating bilateral moyamoya disease. Note smaller spontaneous transdural supply from basal vessels on lateral projection $\left({ }^{*}\right)$. Figure is available in color online only.

tive strokes, confirmed by MRI evidence of acute infarction (read independently by the neuroradiologist on service at the time the MRI was performed as part of routine clinical practice). Strokes were ascribed to interruption of transdural collaterals if a new postoperative stroke was identified that was specific to the transdural supply. For example, in a patient with a new postoperative superior division middle cerebral artery (MCA) stroke that encompassed a small patch of cortex supplied by transdural vessels, the event would not be considered a complication secondary to the collaterals. However, a small cortical infarct directly underlying an area of collaterals would be considered a transdural collateral-related complication. Specifically, each perioperative stroke was subjected to retrospective review by the surgeon and the neuroradiologists (R.M.S., R.R., E.S.) for the purpose of this manuscript. To be called a transdural collateral-related complication, the infarct in question had to meet the following criteria: it had to be 1) acute; 2) limited to just the anatomically concordant area of cortex specifically supplied by a distinct, individual collateral vessel; 3) supplied by a collateral vessel that traversed the operative field; and 4) unanimously agreed upon by the reviewers.

\section{Results}

\section{Demographic Data}

In the study period covered by the IRB approval (January 2005-December 2013), a total of 204 patients (of 507) had full, 5-vessel preoperative catheter arteriograms available for review. Demographic information for the study 

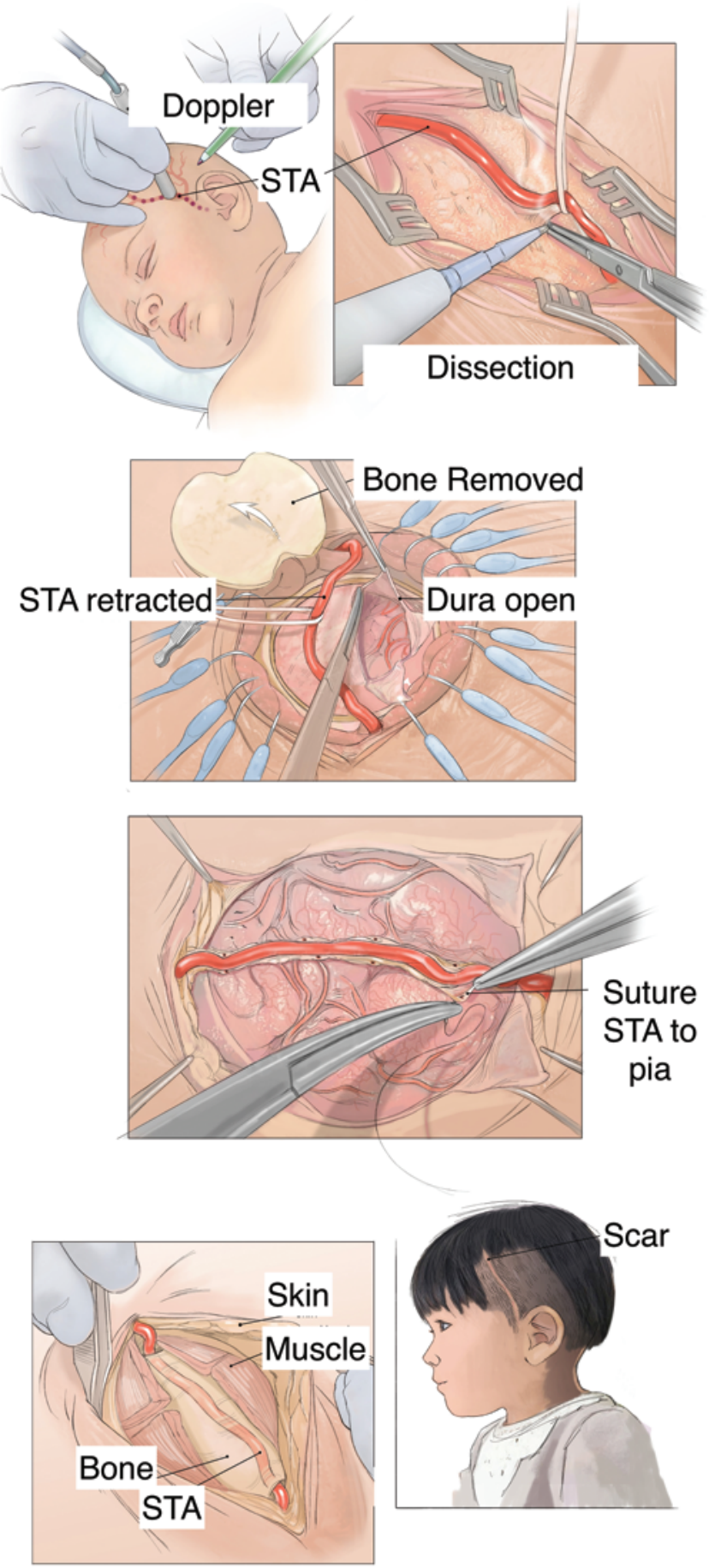

FIG. 2. Schematic representation of pial synangiosis showing sequential steps of isolating and grafting the STA. Note craniotomy flap and opening of dura mater in the middle steps, relevant to potential interruption of transdural collaterals, as further presented in Fig. 3. Copyright Edward

Smith. Published with permission. Figure is available in color online only.

cohort is summarized in Table 1 . There were 121 females $(59 \%)$ and 83 males (41\%) in the group. The average age at time of treatment was 9.5 years (range $0.4-35$ years); most children were treated within several weeks of diagnosis, so the age at diagnosis and treatment averaged out the same.
TABLE 1. Demographic data and clinical presentation in 204 patients with moyamoya

\begin{tabular}{lc}
\hline \multicolumn{1}{c}{ Characteristic } & Value \\
\hline Total no. of pts (Jan 2005-Dec 2013) & 204 \\
\hline Sex & $121(59 \%)$ \\
\hline Female & $83(41 \%)$ \\
\hline Male & 9.5 yrs (range 0.4-35 yrs) \\
\hline Average age at surgery & \\
\hline Clinical findings & $84 \%$ \\
\hline Ischemic symptoms (stroke/TIA) & $36 \%$ \\
\hline Headache & $7 \%$ \\
\hline Incidental & $3 \%$ \\
\hline Chorea & $1 \%$ \\
\hline Hemorrhage &
\end{tabular}

Pts = patients; $\mathrm{TIA}=$ transient ischemic attack .

\section{Clinical Presentation}

The average age at diagnosis was 9.5 years (range $0.4-$ 35 years) and 190 patients had symptoms referable to moyamoya at the time of presentation (93\%). Ischemic symptoms (stroke or transient ischemic attack) were present in 171 patients (84\%), headaches were present in 73 patients (36\%), 6 patients (3\%) presented with chorea, and 2 patients $(1 \%)$ presented with intracranial hemorrhage. Fourteen patients $(7 \%)$ were asymptomatic at presentation.

\section{Radiographic Presentation}

As shown in Table 2, there were 358 affected hemispheres in 204 patients. Bilateral disease was present in 154 patients $(75 \%)$ at presentation (308 hemispheres) and unilateral disease was present in 50 patients (25\%), involving 50 hemispheres (23 [46\%] left, and 27 [54\%] right). Ivy sign, an MRI marker on FLAIR sequences of slow cortical flow, was present in 190 (93\%) hemispheres. Radiographic evidence of stroke was present in $152(75 \%)$ of patients, distributed across $246(69 \%)$ hemispheres.

Transdural collaterals were present in $107(52 \%)$ patients, in nearly half of all hemispheres (176 hemispheres [49\%]). Of 14 patients who had undergone previous cranial surgery unrelated to their moyamoya disease, approximately one-fifth had evidence of transdural collaterals at the surgery site (3/14 patients [21\%]). The primary parent artery of the transdural collaterals was the middle meningeal artery (MMA) in the large majority of cases (150 [85\%]), followed by the STA (16 [9\%]) and maxillary artery $(10[6 \%])$. The average Suzuki grade at presentation was 3.3. Patients with transdural collaterals had higher average Suzuki grades at presentation when compared with patients without transdural collaterals (3.4 vs $3.0, \mathrm{p}$ $=0.002$ ).

\section{Surgical Results}

A total of 324 operations were performed in 204 patients (Table 3). Eighty-four patients (41\%) underwent unilateral surgery, and 120 patients (59\%) underwent bilateral procedures. Of a total of 324 treated hemispheres, 84 (26\%) had collaterals within the area of the surgical field (Fig. 3). 
TABLE 2. Radiographic presentation in 204 patients with moyamoya

\begin{tabular}{|c|c|}
\hline Presentation & Value \\
\hline $\begin{array}{l}\text { Total no. of affected } \\
\text { hemispheres }\end{array}$ & 358 in 204 pts \\
\hline Bilat disease & $\begin{array}{l}154(75 \%) \text { pts } \\
308 \text { hemispheres }\end{array}$ \\
\hline Unilat disease & $\begin{array}{l}50(25 \%) \text { pts } \\
50 \text { hemispheres } \\
23(46 \%) \text { It } \\
27(54 \%) \mathrm{rt}\end{array}$ \\
\hline \multicolumn{2}{|l|}{ MRI findings } \\
\hline Ivy sign & $190(93 \%)$ pts \\
\hline $\begin{array}{l}\text { Radiographic evidence } \\
\text { of stroke }\end{array}$ & $\begin{array}{l}152(75 \%) \text { pts } \\
246(69 \%) \text { hemispheres } \\
121(49 \%) \text { It } \\
125(51 \%) \mathrm{rt}\end{array}$ \\
\hline \multicolumn{2}{|l|}{ Angiographic findings } \\
\hline Transdural collaterals & $\begin{array}{l}107(52 \%) \text { pts } \\
176(49 \%) \text { hemispheres }\end{array}$ \\
\hline $\begin{array}{l}\text { Primary parent arteries } \\
\text { of collaterals }\end{array}$ & $\begin{array}{l}150(85 \%) \text { MMA } \\
16(9 \%) \text { STA } \\
10(6 \%) \text { maxillary }\end{array}$ \\
\hline Suzuki grade & $\begin{array}{l}\text { Average } 3.3 \\
3.4 \text { in hemispheres w/ collaterals* } \\
3.0 \text { in hemispheres w/o collaterals }\end{array}$ \\
\hline $\begin{array}{l}\text { Effect of previous } \\
\text { surgery }\end{array}$ & $\begin{array}{l}3 / 14(21 \%) \text { pts who had cranial surgery } \\
\text { developed collaterals at op site }\end{array}$ \\
\hline
\end{tabular}

\section{Postoperative Complications}

In the 324 operations, there were no deaths (Table 3). Complications included 12 perioperative strokes in 324 hemispheres (3.7\% per hemisphere), with 5 of the strokes directly attributable to interruption of transdural collaterals in the operative field (5/12 [42\%]), as defined by the criteria outlined in the Methods section. The other 7 strokes were not related to the operative field and included 2 large MCA territory infarctions in infants, 4 watershed zone infarctions, and 1 patient with a frontal pole infarction. These other 7 strokes were excluded as transdural collateral-related complications for the following reasons: they 1) involved an entire parent branch (the 2 MCA strokes); 2) had vascular territories that were larger-and discontinuous-with the preoperative areas of perfusion supplied by the transdural collaterals (the watershed infarctions); or 3 ) did not align with the same anatomical location as the areas of perfusion supplied by the transdural collaterals (frontal pole). An example of the type of stroke we would include as a transdural-related surgical complication is demonstrated in Fig. 4.

\section{Angiographic Outcomes}

The 1-year angiographic outcomes were available for 222 hemispheres in 126 patients (Table 4). Overall, Matsushima Grade A surgical collaterals were seen in 54\% of hemispheres, Matsushima Grade B in 28\%, and Mat-
TABLE 3. Surgical results: operations, complications in 204 patients with moyamoya

\begin{tabular}{lc}
\hline \multicolumn{1}{c}{ Op Results } & Value \\
\hline Total no. of ops & 324 (in 204 pts) \\
\hline Unilat & $\begin{array}{c}84 / 324 \text { hemispheres }(26 \%) \text { in } 84 \\
\text { pts (41\%) }\end{array}$ \\
\hline Bilat & $\begin{array}{c}240 / 324 \text { hemispheres }(74 \%) \text { in } 120 \\
\text { pts (59\%) }\end{array}$ \\
\hline Complication & $0(0 \%)$ \\
\hline Death & $12 / 324(3.7 \%$ per hemisphere) \\
\hline Stroke & $5 / 12(42 \%$ of total strokes) \\
\hline $\begin{array}{c}\text { Strokes due to collateral } \\
\text { interruption }\end{array}$ & $7 / 12$ (58\% of total strokes) \\
\hline \multicolumn{2}{c}{ Other strokes } \\
$\begin{array}{l}\text { * Two patients with large MCA strokes (infants), } 4 \text { patients with watershed } \\
\text { infarctions (3 post-radiation for tumor), and } 1 \text { patient with frontal pole infarction. }\end{array}$
\end{tabular}

sushima Grade C in $18 \%$. For patients with preexisting transdural collateral vessels evident before surgery, the postsurgical angiographic Matsushima grades were better than those in patients without evidence of preoperative transdural collaterals $(\mathrm{A}=63 \%$ vs $42 \%, \mathrm{~B}=26 \%$ vs $32 \%$, and $\mathrm{C}=12 \%$ vs $26 \%$; $<<0.003$, 2-tailed Mann-Whitney test).

\section{Discussion}

The ability of the ischemic brain to develop spontaneous networks of vascular collaterals has long been known, but specific analysis of spontaneous transdural collaterals in moyamoya is limited. ${ }^{19,20,24}$ Here we present data from our series of surgically treated patients with moyamoya to better understand the potentially significant clinical and biological implications of this phenomenon, with the goal of defining its potential as a novel radiographic biomarker in this disease. The WHO and the NIH have recently defined a biomarker as "any substance, structure, or process that can be measured in the body... and influences or predicts the incidence of outcome or disease," and the identification and use of these collaterals in this series fits this definition directly. ${ }^{26}$ Our analysis reveals that the prevalence of preoperative transdural collaterals is very high; that the presence of these collaterals correlates with radiographic markers of advanced arteriopathy (and therefore, presumably, ischemia); that interruption of these collaterals at surgery is a major factor in perioperative stroke; and that patients with preoperative transdural collaterals have better postoperative radiographic responses to surgical revascularization.

\section{Transdural Collateral Characteristics and Risk of Perioperative Complications}

The data from this study reveal that spontaneous transdural collaterals existed in approximately half of patients in the series, with the vast majority of collaterals primarily arising from the MMA. Approximately one-quarter of patients with previous surgery had developed angiographically evident collaterals at the surgical site, suggesting 


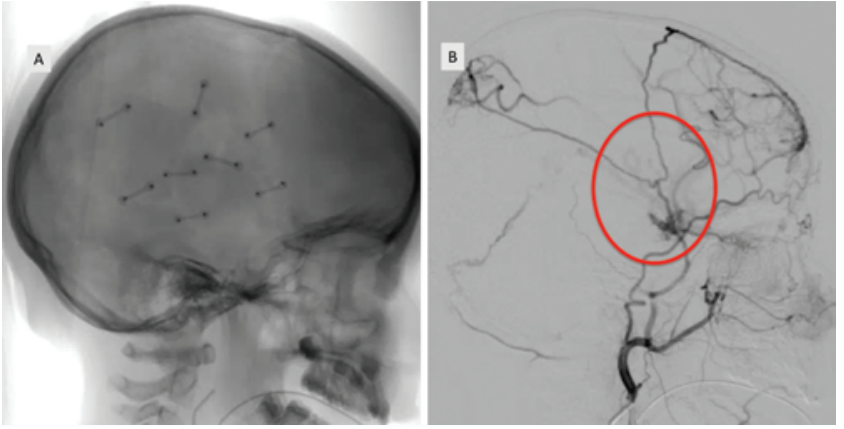

FIG. 3. Lateral unsubtracted (A) postoperative skull radiograph juxtaposed to preoperative (B) lateral ECA injection of catheter angiogram, with a red oval outlining the craniotomy site. Note how the location of the planned craniotomy could potentially interrupt the preexisting MMA collaterals at either the bony opening (if the artery was in proximity to the underside of the skull) or the dural opening. With this information, preoperative planning can provide extra care in the craniotomy and specific preservation of the MMA branches with a tailored dural opening. In this case the craniotomy site was not adjusted, but the dural opening was changed to preserve the continuity of the transdural collateral vessel. Figure is available in color online only.

that any openings provided to the ischemic brain may be used as a corridor for vessel growth. This is concordant with findings in previous reports of collaterals developing at sites of ventriculoperitoneal shunts in patients with moyamoya, and suggests that particular caution should be taken in planning reoperation or revascularization surgery in this population. ${ }^{24}$

Relevant to the discussion of operative planning, it is important to note that nearly half $(42 \%)$ of the perioperative strokes in this series were directly attributable to interruption of preexisting transdural collaterals at the time of surgery, underscoring the need to carefully review the radiographic images, even when routinely obtained. Given that perioperative stroke is the most common complication of revascularization surgery for moyamoya, this finding is critical, because it identifies an immediately modifiable risk factor to potentially reduce complications. . $^{5,12,22,23,28}$ On the one hand, the largest craniotomy and dural opening possible will maximize the area for revascularization. On the other hand, knowledge of preexisting transdural collaterals can allow the surgeon to tailor his or her opening to the greatest possible extent while specifically avoiding identified collaterals.

Although catheter angiography may not be feasible in every patient with moyamoya (due to technical and time limitations, risk of dye reactions, comorbidities, and so on), the data from this study support consideration of its use-including ECA injections-when possible. Future advances in imaging may obviate the need for catheter angiography, but currently, in experienced centers the risk of these studies is low, and this research suggests that there may be substantial benefit to its use to plan operative approaches that avoid interruption of transdural collateral vessels. . $^{2,13,21}$

\section{Association of Collaterals With Ischemia and Relevance to Angiographic Outcomes}

Suzuki grades are predicated on the premise that wors-
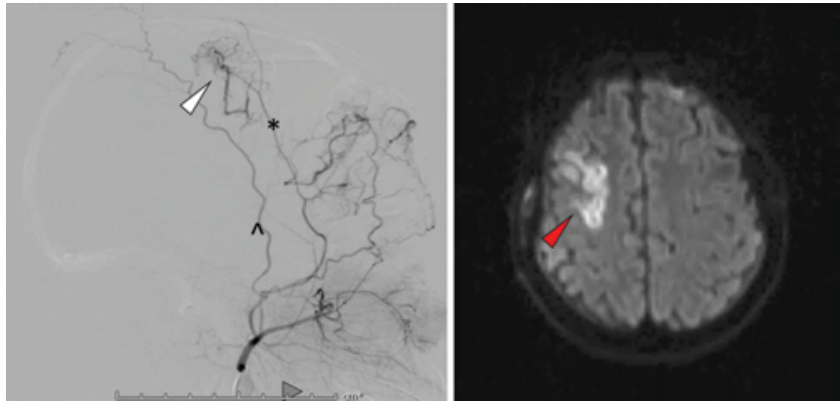

FIG. 4. Left: Lateral unsubtracted preoperative angiogram with an injection of the right ECA showing transdural collaterals supplying the right frontal cortex (arrowhead) with branches from the MMA $\left(^{*}\right)$. There are no branches from the STA $(\wedge)$. Right: Postoperatively the patient had new left-sided weakness, and imaging revealed a new right frontal infarct on MRI (diffusion-weighted imaging) directly in the area supplied by the transdural collaterals (arrowhead). The infarction was not in the immediate operative field (making surgical injury to the subjacent cortex impossible), but correlated exactly with interruption of the MMA branch injured during the surgical approach. Figure is available in color online only.

ening ischemia correlates with increasing basal collateral development until the final stages of complete occlusion of the ICA shut down all blood flow. ${ }^{27}$ Given that cerebral ischemia functions as a biological driver of collateral development, we hypothesized that patients with more severe arteriopathy (and, concomitantly, ischemia) would have a higher prevalence of spontaneous transdural collaterals. ${ }^{9,11,15,19}$ Using the radiographic markers of higher Suzuki grade and ivy sign, we found that the presence of transdural collaterals correlated with markers of worsening ischemia. $3,7,8,10,27,29$

Analysis of our patient population also revealed that the presence of spontaneous transdural collaterals preoperatively significantly correlated with better postoperative angiographic results at 1 year after surgery, as measured by the Matsushima grade. ${ }^{17,18}$ Taken together, these data support the hypothesis that cerebral ischemia stimulates the development of collateral development, both spontaneously and after surgical revacularization. This finding is important because it suggests that it may be possible to predict appropriate candidates for surgery, potentially by using specific radiographic criteria (Suzuki grade, ivy sign, transdural collateral presence). In addition, if the molecular drivers of collateral development can be identified,

TABLE 4. One-year angiographic outcomes in 204 patients with moyamoya

\begin{tabular}{cccc}
\hline $\begin{array}{c}\text { Matsushima } \\
\text { Grade }\end{array}$ & $\begin{array}{c}\text { Preop } \\
\text { Transdural } \\
\text { Collaterals }\end{array}$ & $\begin{array}{c}\text { No Preop } \\
\text { Transdural } \\
\text { Collaterals }\end{array}$ & Total \\
\hline A & $78(63 \%)$ & $41(42 \%)$ & $119(54 \%)$ \\
\hline B & $32(26 \%)$ & $31(32 \%)$ & $63(28 \%)$ \\
\hline C & $15(12 \%)$ & $25(26 \%)$ & $40(18 \%)$ \\
\hline Total & $125(56 \%)$ & $97(44 \%)$ & 222 hemispheres (126 pts) \\
\hline Average $^{*}$ & 1.5 & 1.8 & \\
\hline
\end{tabular}

* Matsushima Grade $A=1, B=2, C=3$. Grades were better in patients with preexisting collateral vessels $(p<0.003)$. 
they could be used as novel biomarkers to select surgical candidates-and could theoretically also have utility as surgical adjuncts to augment revascularization.

\section{Limitations and Future Directions}

First, our data focused on a predominantly pediatric population, and it is important to acknowledge this skew in the age of our patients. However, limited data from adult moyamoya patients are concordant with our results and reinforce the general applicability of our findings. The prevalence of preoperative transdural collaterals in a study of adults (42\%; $27 / 64$ hemispheres) was slightly lower but nonetheless similar to our data (49\% of 176 hemispheres), although location, effects on complications, and relationship to outcome were not reported in the adult series. ${ }^{6}$ To our knowledge, our series is the largest to date, but clearly this work would benefit from further validation by a larger, multicenter study.

Second, whereas our measures of radiographic ischemia are well validated and include both angiographic (Suzuki grade) and MRI (ivy sign) data, they do differ from some other reported methods of evaluation. Radiographic measures of ischemia, including cerebral blood flow, oxygen extraction fraction, and cerebral blood volume, were studied in 10 adult patients with moyamoya by using PET, and the presence of transdural collaterals correlated with increased cerebral ischemia. ${ }^{20}$ Although PET studies are generally avoided in our practice due to their exposure of children to radiation and the additional need for sedation in the pediatric population, the premise that preexisting cerebral ischemia spurs collateral growth meshes nicely with our findings that children with preoperative transdural collaterals also demonstrate radiographic evidence of more severe ischemia at presentation (Suzuki stage and ivy sign) and exhibit a trend toward better growth of postoperative collaterals after surgery (as measured by Matsushima grade). It is important to note that we are not advocating replacing other types of studies with catheter angiographyrather, we present these data to underscore the importance of continuing catheter angiography as one part of the diagnostic workup of patients with moyamoya and to highlight new findings that add to its ongoing utility.

Third, although this work describes the phenomenon of transdural collateral prevalence and the clinical implications of its presence, it does not offer direct insight into the mechanistic drivers of growth. Future studies will focus on the biological underpinnings of transdural collateral development.

Fourth, we recognize that it is ultimately impossible to directly relate interruption of transdural collaterals to postoperative stroke, absent the (currently impractical) ability to perform intraoperative, real-time imaging to observe infarction occurring concurrently with transdural collateral interruption. Consequently, although there will always remain a potential question of whether any given stroke might be coincidental and not causal from collateral interruption, we hope that the stringent criteria we have applied (as outlined in our Methods section and as exemplified in Fig. 4) for defining a transdural-related stroke will help to minimize false-positive reporting. Independent of the methods used to quantify transdural collateral-related stroke, we believe that this report will be helpful to surgeons by providing an analysis of the overall prevalence of transdural collaterals in pediatric moyamoya.

Fifth, we recognize that there are risks inherent to the use of catheter angiography, including arterial injury, stroke, and radiation exposure. Although these risks are rare in experienced centers, we remain committed to finding alternatives to DSA. Doppler ultrasonography is a useful tool to identify the presence of vessels, and may be a useful adjunct to other imaging tools. However, because it is currently unable to reliably identify vessels through bone, it may be limited in its ability to find collateral vessels that supply the cortex and that run under bone (such as meningeal branches) outside of the surgical field. To date, our investigations with MRA and CT angiography have not been able to replicate the sensitivity and resolution offered by DSA. However, we currently are conducting trials for a new method of CT angiographic imaging, and hope to report on the results of this work in the near future.

\section{Conclusions}

Spontaneous transdural collaterals were present in nearly half of all patients with moyamoya in our series. These vessels are more common in patients with advanced disease, are associated with stroke as a perioperative complication, and may suggest increased capacity to produce surgical collaterals postoperatively. These data support the use of preoperative catheter angiography with ECA injections as an important component in the diagnostic workup of patients with moyamoya (in conjunction with other imaging modalities), offer an opportunity to reduce perioperative complications related to stroke, and suggest novel methods to develop biomarkers capable of stratifying surgical candidates and predicting outcome.

\section{Acknowledgments}

We acknowledge the Marcus Chae Moyamoya Research Fund and the Kids at Heart Neurosurgery Research Fund.

\section{References}

1. Adelson PD, Scott RM: Pial synangiosis for moyamoya syndrome in children. Pediatr Neurosurg 23:26-33, 1995

2. Burrows PF, Robertson RL, Barnes PD: Angiography and the evaluation of cerebrovascular disease in childhood. Neuroimaging Clin N Am 6:561-588, 1996

3. Fujiwara H, Momoshima S, Kuribayashi S: Leptomeningeal high signal intensity (ivy sign) on fluid-attenuated inversionrecovery (FLAIR) MR images in moyamoya disease. Eur J Radiol 55:224-230, 2005

4. Fukui M: Guidelines for the diagnosis and treatment of spontaneous occlusion of the circle of Willis ('moyamoya' disease). Research Committee on Spontaneous Occlusion of the Circle of Willis (Moyamoya Disease) of the Ministry of Health and Welfare, Japan. Clin Neurol Neurosurg 99 (Suppl 2):S238-S240, 1997

5. Jackson EM, Lin N, Manjila S, Scott RM, Smith ER: Pial synangiosis in patients with moyamoya younger than 2 years of age. J Neurosurg Pediatr 13:420-425, 2014

6. Jo KI, Yeon JY, Hong SC, Kim JS: Clinical course of asymptomatic adult moyamoya disease. Cerebrovasc Dis 37:94101, 2014

7. Jung MY, Kim YO, Yoon W, Joo SP, Woo YJ: Characteristics 
of brain magnetic resonance images at symptom onset in children with moyamoya disease. Brain Dev 37:299-306, 2015

8. Kawashima M, Noguchi T, Takase Y, Nakahara Y, Matsushima T: Decrease in leptomeningeal ivy sign on fluid-attenuated inversion recovery images after cerebral revascularization in patients with Moyamoya disease. AJNR Am J Neuroradiol 31:1713-1718, 2010

9. Kusaka N, Sugiu K, Tokunaga K, Katsumata A, Nishida A, Namba K, et al: Enhanced brain angiogenesis in chronic cerebral hypoperfusion after administration of plasmid human vascular endothelial growth factor in combination with indirect vasoreconstructive surgery. J Neurosurg 103:882-890, 2005

10. Lee JK, Yoon BH, Chung SY, Park MS, Kim SM, Lee DS: The usefulness of the ivy sign on fluid-attenuated intensity recovery images in improved brain hemodynamic changes after superficial temporal artery-middle cerebral artery anastomosis in adult patients with moyamoya disease. J Korean Neurosurg Soc 54:302-308, 2013

11. Lim M, Cheshier S, Steinberg GK: New vessel formation in the central nervous system during tumor growth, vascular malformations, and moyamoya. Curr Neurovasc Res 3:237245, 2006

12. Lin N, Aronson JP, Manjila S, Smith ER, Scott RM: Treatment of moyamoya disease in the adult population with pial synangiosis. J Neurosurg 120:612-617, 2014

13. Lin N, Smith ER, Scott RM, Orbach DB: Safety of neuroangiography and embolization in children: complication analysis of 697 consecutive procedures in 394 patients. J Neurosurg Pediatr 16:432-438, 2015

14. Maeda M, Tsuchida C: "Ivy sign" on fluid-attenuated inversion-recovery images in childhood moyamoya disease. AJNR Am J Neuroradiol 20:1836-1838, 1999

15. Malek AM, Connors S, Robertson RL, Folkman J, Scott RM: Elevation of cerebrospinal fluid levels of basic fibroblast growth factor in moyamoya and central nervous system disorders. Pediatr Neurosurg 27:182-189, 1997

16. Matsushima T, Inoue T, Suzuki SO, Fujii K, Fukui M, Hasuo $\mathrm{K}$ : Surgical treatment of moyamoya disease in pediatric patients-comparison between the results of indirect and direct revascularization procedures. Neurosurgery 31:401-405, 1992

17. Matsushima Y, Aoyagi M, Fukai N, Tanaka K, Tsuruoka S, Inaba Y: Angiographic demonstration of cerebral revascularization after encephalo-duro-arterio-synangiosis (EDAS) performed on pediatric moyamoya patients. Bull Tokyo Med Dent Univ 29:7-17, 1982

18. Matsushima Y, Inaba Y: The specificity of the collaterals to the brain through the study and surgical treatment of moyamoya disease. Stroke 17:117-122, 1986

19. Nishijima Y, Akamatsu Y, Weinstein PR, Liu J: Collaterals: Implications in cerebral ischemic diseases and therapeutic interventions. Brain Res 1623:18-29, 2015
20. Piao R, Oku N, Kitagawa K, Imaizumi M, Matsushita K, Yoshikawa T, et al: Cerebral hemodynamics and metabolism in adult moyamoya disease: comparison of angiographic collateral circulation. Ann Nucl Med 18:115-121, 2004

21. Robertson RL, Chavali RV, Robson CD, Barnes PD, Eldredge EA, Burrows PE, et al: Neurologic complications of cerebral angiography in childhood moyamoya syndrome. Pediatr Radiol 28:824-829, 1998

22. Scott RM, Smith ER: Moyamoya disease and moyamoya syndrome. N Engl J Med 360:1226-1237, 2009

23. Scott RM, Smith JL, Robertson RL, Madsen JR, Soriano SG, Rockoff MA: Long-term outcome in children with moyamoya syndrome after cranial revascularization by pial synangiosis. J Neurosurg 100 (2 Suppl Pediatrics):142-149, 2004

24. Singla A, Lin N, Ho AL, Scott RM, Smith ER: Vascular collateralization along ventriculoperitoneal shunt catheters in moyamoya disease. J Neurosurg Pediatr 11:710-712, 2013

25. Smith ER, Scott RM: Spontaneous occlusion of the circle of Willis in children: pediatric moyamoya summary with proposed evidence-based practice guidelines. A review. J Neurosurg Pediatr 9:353-360, 2012

26. Strimbu K, Tavel JA: What are biomarkers? Curr Opin HIV AIDS 5:463-466, 2010

27. Suzuki J, Takaku A: Cerebrovascular "moyamoya" disease. Disease showing abnormal net-like vessels in base of brain. Arch Neurol 20:288-299, 1969

28. Veeravagu A, Guzman R, Patil CG, Hou LC, Lee M, Steinberg GK: Moyamoya disease in pediatric patients: outcomes of neurosurgical interventions. Neurosurg Focus 24(2):E16, 2008

29. Yoon HK, Shin HJ, Chang YW: "Ivy sign" in childhood moyamoya disease: depiction on FLAIR and contrast-enhanced T1-weighted MR images. Radiology 223:384-389, 2002

\section{Disclosures}

The authors report no conflict of interest concerning the materials or methods used in this study or the findings specified in this paper.

\section{Author Contributions}

Conception and design: Smith, Scott, Robertson. Acquisition of data: Storey. Analysis and interpretation of data: all authors. Drafting the article: Smith, Scott. Critically revising the article: Smith, Scott, Robertson. Reviewed submitted version of manuscript: Smith. Approved the final version of the manuscript on behalf of all authors: Smith. Administrative/technical/material support: Storey.

\section{Correspondence}

Edward Smith, Department of Neurosurgery, Boston Children's Hospital, 300 Longwood Ave., Boston, MA 02115. email: edward. smith@childrens.harvard.edu. 